Isabel Lifante Vidal

«INTERPRETACIÓN Y MODELOS
DE DERECHO. SOBRE EL PAPEL
DE LA INTENCIÓN EN LA
INTERPRETACIÓN JURÍDICA»

DOXA 22 (1999) 


\title{
INTERPRETACIÓN Y MODELOS DE DERECHO. SOBRE EL PAPEL DE LA INTENCIÓN EN LA INTERPRETACIÓN JURÍDICA
}

\author{
Isabel Lifante \\ Universidad de Alicante
}

\section{Introducción}

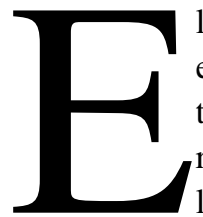

1 objetivo del presente artículo ${ }^{1}$ es analizar una discusión que, en los últimos años, ha cobrado gran auge en el ámbito de la teoría de la interpretación jurídica y que puede verse como el resurgimiento de la clásica polémica a propósito del papel de las intenciones en la interpretación del Derecho. Lo que caracterizaría al planteamiento actual de esta discusión sería que, en ella, la argumentación principal que dan los intencionalistas a favor de sus tesis se encuentra estrechamente vinculada al análisis de la noción de autoridad.

El origen de esta discusión puede situarse en la crítica que Marmor dirige al modelo dworkiniano de interpretación jurídica; como es sabido, éste es un modelo constructivo o dependiente de valores, que apenas concede importancia a las intenciones de los creadores del Derecho. Por su parte, las tesis de Marmor toman como punto de partida el modelo de Derecho sugerido por Raz, siendo el soporte básico de su argumentación el análisis de la noción de autoridad desarrollado por este autor. También el propio Raz ha intervenido en la polémica, y aunque sus tesis intencionalistas tienen un alcance algo más limitado respecto a la interpretación que las de Marmor, en algunos puntos su argumentación me parece más desarrollada. Seguiré, por tanto, el hilo expositivo que utiliza Marmor y expondré a continuación las tesis de Raz.

Esta discusión se ha planteado, en mi opinión, en unos términos particularmente confusos. Sin menospreciar la complejidad aportada por el tema general en el que se integra, el de la interpretación jurídica, creo que los mayores problemas vienen originados por el escurridizo concepto de «intención». Sin embargo, no analizaré a fondo este intrincado concepto, sino que me limitaré a señalar los distintos significados con los que se usa dicho tér-

${ }^{1}$ Este artículo reproduce, con escasas modificaciones, la ponencia presentada al IV Congreso Hispano-Italiano de Teoría del Derecho, celebrado en Almagro en octubre de 1998. 
mino en el ámbito de la discusión; estas aclaraciones nos permitirán precisar en alguna medida las posturas sostenidas por Raz y Marmor. Mi principal conclusión será, sin embargo, que sus tesis difícilmente pueden calificarse de «intencionalistas» respecto a la interpretación jurídica. Para finalizar, y quizás con el «inconfesable» propósito de justificar en alguna medida el título del trabajo, intentaré conectar las tesis analizadas con el concreto modelo de Derecho con el que operan sus partidarios, señalando las deformaciones que dicha perspectiva puede originar en la caracterización de la interpretación jurídica.

\section{Las tesis intencionalistas de Marmor}

En su libro Interpretation and Legal Theory, Marmor define la interpretación en general como «la imposición de significado a un objeto», e intenta determinar cuál sería la concepción apropiada de «significado» para este concepto de interpretación. Con este fin, analiza las posibles respuestas a esta cuestión: una noción semántica de «significado», lo que podría considerarse como el significado de un objeto [meaning of]; y una noción pragmática de «significado», esto es, lo que el autor quiere decir por medio del objeto [meaning that $]^{2}$. La primera noción es rechazada, porque -para Marmor- el significado semántico de una expresión está, al menos en el contexto lingüístico, básicamente determinado por reglas o convenciones, mientras que la interpretación sería una excepción al entendimiento estándar del lenguaje y de la comunicación ${ }^{3}$ y, a diferencia de éste, no estaría gobernada por reglas. Marmor se decanta, por tanto, por la otra noción disponible de significado, la pragmática, proponiendo así un concepto de interpretación en términos de atribución de intenciones comunicativas (Marmor, 1992, pp. 30 y ss.). Aunque, como no todas las interpretaciones pueden verse como descripciones de lo que un hablante quiso decir, Marmor amplía la noción pragmática de significado, incluyendo también la atribución de intenciones contrafácticas. Un enunciado interpretativo es así, para Marmor, o bien «un enunciado sobre las intenciones comunicativas del hablante

\footnotetext{
${ }^{2}$ Estas dos nociones de significado pueden considerarse paralelas a las nociones básicas que distingue Grice en su artículo «Las intenciones del hablante», denominadas por él «significado atemporal» (que coincidiría con el significado del objeto) y «significado ocasional» (que coincidiría con el significado para el autor). La clasificación de Grice es, sin embargo, algo más compleja. Dentro del significado ocasional, este autor distingue entre lo que llama «significado ocasional de una proferencia tipo», que sería el que estaría en juego en proposiciones con la forma: «Con X (proferencia tipo) H quiso decir “...”»; y lo que llama «significado ocasional del hablante», que se encontraría en especificaciones del tipo: «Al proferir $\mathrm{X}, \mathrm{H}$ quiso decir que ...» (Grice, 1991, pp. 481-485).

${ }^{3}$ Esta «tesis de la excepción» defendida por Marmor a propósito de la interpretación se encuentra desarrollada extensamente en el cap. 2 de su libro (Marmor, 1992, pp. 13-34).
} 
real», o bien «un enunciado contrafáctico, que caracteriza las intenciones comunicativas de un hablante ficticio, cuya identidad y naturaleza son o explícitamente definidas o [...] presupuestas por la concreta interpretación ofrecida» (Marmor, 1992, p. 31). Y será precisamente esta supuesta identidad y caracterización del hablante ficticio lo que determine el criterio de valoración presupuesto por el tipo de interpretación de que se trate ${ }^{4}$.

Centrémonos en la interpretación del Derecho. En este ámbito, Marmor pretende presentar su concepción como una alternativa a las tesis de Dworkin; frente al modelo constructivo o basado en valores que este último defiende, Marmor se muestra partidario de un modelo intencional o comunicativo. Ahora bien, para que las tesis de Marmor resulten relevantes como alternativa a la concepción de Dworkin, las intenciones a las que se hace referencia en esta interpretación han de ser intenciones reales y no meramente ficticias o contrafácticas ${ }^{5}$. Y ello porque resultaría prácticamente equivalente decir que una determinada interpretación es la que muestra un objeto bajo su mejor ángulo -como diría Dworkin-, que considerar que esa interpretación responde a las intenciones de un autor ficticio, al que podemos suponer las intenciones de crear «el mejor Derecho posible» ${ }^{6}$. En otras palabras, creo que las concepciones «generales» de la interpretación sostenidas por Marmor y por Dworkin no resultan tan incompatibles como el propio Marmor parece suponer, o mejor dicho, que el modelo de interpretación de Dworkin puede tener cabida en la concepción general de la interpretación sostenida por Marmor ${ }^{7}$; las diferencias habrán de encontrarse, en su caso, en lo que, para cada uno de estos autores, constituyen los específicos criterios de valoración de la interpretación jurídica. Analicemos, por tanto, el papel concedido por Marmor a las intenciones en este tipo de interpretación.

Marmor considera que, en el ámbito del Derecho, es posible dar dos versiones distintas del intencionalismo que no se encuentran implicadas entre sí. La primera tiene que ver con la identificación de una norma jurídica co-

${ }^{4}$ Marmor considera en este punto, y a diferencia de Dworkin, que la interpretación no tiene por qué implicar siempre un mismo criterio de valoración (Marmor, 1992, pp. 34, 51 y ss.).

${ }_{5}^{5}$ Creo que esta idea -aunque no recogida expresamente- subyace al análisis de Marmor; incluso en algún momento (refiriéndose a las que llama «intenciones en cuanto a la aplicación»), realiza una observación de este tipo (Marmor, 1992, pp. 170-171).

${ }^{6}$ En un sentido similar a éste se pronuncia Endicott (1994, p. 456).

${ }^{7}$ Dworkin considera, al igual que Marmor, que toda interpretación debe, necesariamente, hacer referencia a propósitos, señalando que la intención a la que se refiere no tiene por qué ser entendida necesariamente como un estado mental. Toda interpretación debe proponer una manera de ver el objeto interpretado como si se tratara del producto de la decisión de buscar un conjunto de temas, visiones o propósitos, es decir, un «sentido», y esto es así incluso cuando no exista un autor histórico del que pueda predicarse dicho propósito (Dworkin, 1986, p. 59). 
mo tal y la segunda, con la determinación del significado de la norma, con su interpretación (Marmor, 1992, p. 105).

\section{La primera versión del intencionalismo}

Respecto a la primera versión del intencionalismo, Marmor sostiene que las intenciones desempeñan un rol crucial en la identificación de las normas jurídicas; según él, algo sólo puede ser identificado como una norma jurídica si se presume que ha sido creado como tal. A partir de las tesis de Raz, la justificación a la que alude Marmor se basa en una concepción personal de la autoridad, que podría esquematizarse como sigue: (1) El Derecho es inteligible sólo si pretende tener autoridad legítima; (2) para que algo sea susceptible de pretender autoridad, debe ser un tipo de cosa capaz de tenerla; y (3) sólo las personas, que pueden comunicarse con otros, son capaces de tener autoridad (Marmor, 1995, pp. 311-312).

Esta concepción personal de la autoridad -advierte Marmor- supone que la autoridad del Derecho sólo puede basarse en la autoridad de sus autores, pero no implica que sean las características personales del autor las que lo convierten en autoridad. «No consideramos - dice Marmor- a ciertas personas como autoridades porque ellas tengan ciertas características personales, sino porque actúan en una función o cargo de autoridad. Es la identidad del cargo y no la identidad personal lo que importa [...] No hay -continúa- nada realmente personal acerca de la concepción personal de la autoridad». La única presuposición de esta concepción sería entonces que «alguien» en el cargo de autoridad debe haber dictado el Derecho (Marmor, 1995, pp. 325-326).

A esta tesis subyace «un modelo comunicativo de Derecho». El Derecho es visto básicamente como un producto de comunicación: el producto de una autoridad que expresa sus puntos de vista sobre la conducta deseable de sus sujetos. Este modelo puede tener algunos inconvenientes en el caso de la costumbre. Marmor es consciente de ello y admite que la concepción personal de la autoridad no se adecua completamente a estos casos, pero señala que también las costumbres reflejan el punto de vista de «alguien» (gran parte de la comunidad), acerca de cómo deben comportarse los individuos; de modo que podría considerarse que son una estructura «informal» de expresión colectiva, que resultaría en cierta medida equivalente a las estructuras formales de decisión colectiva (Marmor, 1995, p. 329).

No me detendré más en esta primera versión del intencionalismo, ya que, por un lado, no se relaciona directamente con la interpretación del Derecho, sino con su identificación y, por otro, coincide en gran medida con la tesis de la intención de la autoridad defendida por Raz, de la que luego me ocuparé. 


\section{La segunda versión del intencionalismo}

La segunda versión del intencionalismo sí que tiene que ver con la interpretación del Derecho. En este punto, Marmor sintetiza su postura en las dos siguientes tesis: 1) las leyes, al menos en ciertos casos, son promulgadas con intenciones específicas y ésta es una cuestión de hecho que es distinguible del procedimiento para poder probar ese hecho; y 2) en ciertos casos, la presencia de tal circunstancia (que una ley haya sido promulgada con una intención específica) suministra al juez una razón para decidir una disputa jurídica de acuerdo con la intención legislativa (Marmor, 1992, p. 156). Su argumentación se desarrolla, pues, en dos niveles: (1) un nivel descriptivo, que intenta mostrar que es posible identificar tanto al «legislador» cuyas intenciones deben tenerse en cuenta, como al tipo de intenciones que son potencialmente relevantes para la interpretación jurídica; y (2) un nivel justificativo, que se preocupa de determinar por qué, y cuándo, está justificado acudir a las intenciones legislativas para la interpretación del Derecho.

(1) Empecemos por el nivel descriptivo. Aquí nos encontramos como primer problema con el hecho de que el legislador no suele ser una única persona, sino un cuerpo legislativo compuesto por numerosos miembros. ¿Cómo pueden atribuirse intenciones a un órgano de este tipo? Marmor rechaza la posibilidad de recurrir aquí a la noción de «intenciones representativas», pues ésta exige que se identifiquen ciertos individuos cuyas intenciones cuenten como la intención del órgano mismo, lo que requiere la existencia de un conjunto de reglas o convenciones que determinen esas cuestiones; convenciones que no suelen existir respecto a las intenciones de los legisladores. Para escapar a la crítica de los «escépticos radicales», según la cual la intención sería un predicado mental y por tanto sólo atribuible a los que poseen capacidades mentales (los individuos considerados aisladamente), Marmor alude a la distinción entre la idea de «intención de un grupo», que sería la rechazada por los escépticos, y la de «intenciones compartidas», que aquéllos parecen ignorar (Marmor, 1992, 162-163). Atribuir estas «intenciones compartidas» a un grupo no es -señala Marmor- una cuestión puramente cuantitativa (acerca de cuántos miembros de cierto grupo comparten una determinada intención), sino que es necesario que se dé un elemento adicional: que exista una conexión no accidental entre la identificación del grupo como tal y la intención pertinente. Así, por ejemplo, puede hablarse de que una nación aspira a la independencia; en este caso, aquéllos que comparten la intención pertinente también comparten la expectativa de que su intención sea respaldada por su grupo como tal. Sin embargo, no tendría sentido hablar de que la nación tiene la intención de comer grandes cantidades de fresas, y ello -dice Marmor- porque dicha intención no tiene 
nada que ver con la identificación del grupo como nación. Trasladándose al ámbito jurídico, considera que la intención legislativa será considerada pertinente cuando la mayoría de los legisladores compartan una intención particular de cara a la ley que han promulgado; en estos casos no cabe duda de que dicha intención presenta una conexión no sólo accidental con la identificación del cuerpo legislativo como tal, y ello porque la función de los legisladores es precisamente promulgar leyes ${ }^{8}$.

Los legisladores pueden, entonces, compartir intenciones de cara a las leyes que han promulgado; pero, del mismo modo, también podrían tener intenciones confrontadas. Sin embargo, Marmor considera que éste no es un obstáculo insalvable para sus tesis. Pese a que en algunos casos sea particularmente difícil determinar de quién son las intenciones que deben contar, no siempre será así; en muchas ocasiones -sostiene Marmor- los legisladores comparten intenciones y propósitos bien definidos y tratan de llevar a cabo estas intenciones promulgando una determinada ley, y aunque las ocasiones en que dichas intenciones puedan identificarse sean raras, eso no quiere decir -concluye Marmor- que deban ignorarse (Marmor, 1992, p. 163).

Pero aún queda pendiente otro problema. Cuando una persona lleva a cabo una acción, especialmente si se trata de una acción compleja como legislar, puede tener simultáneamente varias intenciones; debemos determinar cuáles de ellas resultan relevantes para la interpretación del Derecho, si alguna resulta más importante que las otras o cómo combatir los casos en que las distintas intenciones resulten incoherentes entre sí (Marmor, 1992, pp. 165-172). Con este propósito, Marmor distingue dos tipos de intenciones que considera potencialmente relevantes para la interpretación jurídica: las intenciones entendidas como aquello que el legislador pretende conseguir promulgando una norma (a las que llama «intenciones ulteriores» [further intentions]); y los pensamientos o asunciones del legislador a propósito del alcance de la aplicación de esa norma (las «intenciones en cuanto a la aplicación»).

Respecto a las primeras, Marmor considera que, normalmente, cuando se legisla, suelen existir diversos propósitos o intenciones ulteriores; así, por ejemplo, con la prohibición de la entrada de vehículos en el parque, los legisladores pueden pretender proteger la seguridad de los usuarios del parque, salvaguardar un espacio verde en medio de la ciudad, ganar popularidad entre un sector de la población... El principal problema que aquí se plantea es cómo determinar cuáles de estas intenciones ulteriores resultan

\footnotetext{
${ }^{8}$ Como intentaré mostrar al final del trabajo, esta caracterización que hace Marmor de las «intenciones compartidas» me parece inconsistente.
} 
jurídicamente relevantes o legítimas. Para ello, Marmor se pregunta si puede establecerse un criterio independiente del contexto particular de cada caso o si, por el contrario, la distinción entre intenciones legítimas e ilegítimas sólo puede trazarse atendiendo a las consideraciones morales y políticas que afectan al caso. En su opinión, sí puede darse al menos un criterio parcialmente independiente; criterio que se conecta con el particular acto de habla del que se trate. Del mismo modo -dice Marmor- que en el acto de «insinuar», las intenciones ulteriores del hablante son «esencialmente no admisibles o confesables» y el hacerlas explícitas haría fracasar el acto de habla ${ }^{9}$, en el caso de la legislación puede servir como condición suficiente para identificar las intenciones ulteriores que de entrada repugnaría tomar en cuenta, el hecho de que el legislador no esté dispuesto a confesarlas; existiendo, a la inversa, un fuerte elemento de auto-fracaso en hacer tales intenciones explícitas. Pero se trata -dice Marmor- de un criterio parcial que necesita ser complementado con otras consideraciones, principalmente morales (Marmor, 1992, pp. 167-168).

Pasemos al otro tipo de intenciones. Los legisladores tienen a menudo ciertas intenciones o expectativas respecto a la aplicación, por parte de los tribunales, de la ley que han promulgado y estas «intenciones aplicativas» pueden resultar, en opinión de Marmor, relevantes para la interpretación jurídica (Marmor, 1992, pp. 168 y ss.). Conviene notar que, dada la «tesis de la excepción» sostenida por Marmor, este autor se refiere aquí a intenciones que afecten a un caso no incluido en el núcleo claro de significado de la norma ${ }^{10}$. Así, por ejemplo, ante la pregunta acerca de si la norma «Prohibida la entrada de vehículos en el parque» se aplica o no a las bicicletas, sería relevante este tipo de intención si los legisladores, de hecho ${ }^{11}$, tuvieron, al promulgar tal norma, la intención de que la misma fuera aplicada (o no) a las bicicletas.

En opinión de Marmor, estas intenciones en cuanto a la aplicación se conectan con las intenciones ulteriores a través de una relación de tipo medio

${ }^{9}$ Quiero llamar la atención sobre el salto que, en mi opinión, se produce en la argumentación de Marmor en este punto. En el caso del acto de habla de insinuar, lo que resulta «por definición» no confesable es el alcance o significado preciso de lo que quiero decir, no las «intenciones ulteriores» por las que insinúo algo. Yo puedo perfectamente confesar que mi insinuación pretende despertar la curiosidad de mi oyente, sin que ello haga fracasar mi acto de «insinuar».

${ }^{10}$ En los casos claros, se trataría de intenciones «patentes en la comunicación» que formarían parte del significado determinado por reglas y convenciones, y resultarían por tanto relevantes para la comprensión de la norma, pero no para su interpretación (véase Marmor, 1992, pp. 24 y ss.).

${ }^{11}$ Marmor descarta aquí expresamente el recurso a las intenciones contrafácticas: no se trata de determinar cuál hubiera sido la intención del legislador si se le hubiera planteado el caso (Marmor, 1992, p. 169). 
a fin: si se pretende que una norma se aplique a un determinado caso será porque se considera que dicha aplicación es un instrumento adecuado para la consecución del fín o propósito perseguido (Marmor, 1992, p. 171). De este modo, el legislador no puede mantener, sin resultar incoherente, que sus intenciones en cuanto a la aplicación de la norma tengan preferencia sobre sus intenciones ulteriores ${ }^{12}$. A partir de aquí, Marmor considera que el primer tipo de intención siempre va a tener preferencia sobre el segundo: «las intenciones de los legisladores en cuanto a la aplicación deberán ser tomadas en cuenta sólo si y hasta el extremo en que, estén de acuerdo con sus intenciones ulteriores» (Marmor, 1992, p. 172).

(2) Pasemos al nivel justificativo. En opinión de Marmor, las razones para acudir a las intenciones de los legisladores en la interpretación de las leyes ${ }^{13}$ pueden derivarse únicamente de las razones para obedecer prioritariamente a las autoridades jurídicas, aunque ello no implica considerar que siempre que existan razones para obedecer a las autoridades jurídicas existirán también razones para interpretar sus normas de acuerdo con sus intenciones. Partiendo de la tesis de Raz, Marmor distingue dos tipos de razones para el reconocimiento de la legitimidad de una autoridad: la tesis de la pericia y la tesis de la coordinación, y limita su argumento en favor de la intención del legislador estrictamente a la tesis de la pericia, es decir, a aquellos casos en los que la legislatura es correctamente calificada como perita o experta acerca del tema particular que ha promulgado, y hasta el punto en que lo sea (Marmor, 1995, p. 310). En los casos en que opere la tesis de la coordinación no puede considerarse que haya razones para acudir a las intenciones de los legisladores. De este modo y puesto que no cabe aceptar la idea de expertos en moral, Marmor considera que su tesis no resulta aplicable a la legislación cuyos motivos se hallan en la política partidista o en materias ideológicamente controvertidas (Marmor, 1992, p. 181). Pero, incluso por lo que respecta a la tesis de la pericia, las razones para acudir a las intenciones de los legisladores no poseen -según Marmor- un peso absoluto, sino que su fuerza dependerá del grado de pericia que se les presuma a los legisladores. Por último, Marmor admite que estos argumentos podrían igualmente funcionar a favor de acudir a los trabajos preparatorios (que no

${ }_{12}$ Por supuesto, es posible que el legislador esté equivocado (o sea insincero), y que como cuestión de hecho aplicar la regla al caso que él pretende sea inconsistente con la intención de conseguir un cierto objetivo, pero en estos casos -dice Marmor (1992, p. 171)- el legislador tendría que admitir o bien que sus intenciones en cuanto a la aplicación eran inadecuadas, o bien que aquéllos no eran en realidad sus objetivos.

${ }^{13}$ Marmor advierte que su análisis se circunscribe sólo al caso de la interpretación de las leyes y deja fuera expresamente el caso de la interpretación constitucional (Marmor, 1992, pp. 172-173). 
tienen por qué ser obra de los legisladores), y señala también que el factor tiempo es aquí relevante: cuanto más antigua sea una norma menos interesante resultará el intencionalismo (Marmor, 1992, pp. 179-184).

\section{La tesis de la intención de la autoridad de $\operatorname{Raz}$}

En su artículo «La intención en la interpretación», Raz empieza rechazando lo que considera la «tesis radical de la intención», según la cual una interpretación en Derecho sólo es correcta si refleja la intención de su autor, y se muestra partidario -en cambio- de una versión más débil del intencionalismo a la que denomina la «tesis de la intención de la autoridad» y que formula como sigue:

«En la medida en que el Derecho deriva de la legislación deliberada, su interpretación debe reflejar las intenciones de su legislador»(Raz, 1997, p. 209).

En su opinión, la razón para apelar a la intención del autor del objeto a interpretar reside en el hecho de que la justificación -real o supuesta- de confiar los poderes de legislar a algunas instituciones no tiene sentido excepto si las leyes hechas por aquellas instituciones son las leyes que intentan hacer; la tesis tiene, por tanto, un alcance limitado a los actos de creación deliberada de Derecho.

Las intenciones que resultan relevantes para la interpretación han de ser intenciones reales del legislador; si se trata de intenciones ficticias -dice Raz-, la tesis se volvería no sólo irrelevante ${ }^{14}$, sino incluso rechazable por la confusión que generaría. Y el primer problema que se encuentra a la hora de hablar de estas intenciones reales reside en que la mayoría de los legisladores son instituciones y no seres humanos individuales; hay por tanto que determinar cómo puede hablarse de intenciones de una institución. Pero, respecto a esta cuestión, Raz simplemente señala que si estos órganos pueden actuar intencionalmente después de mucha deliberación, entonces también pueden tener intenciones. Estas intenciones dependerán necesariamente de las intenciones de los individuos, pero no se deben confundir con las mismas. La cuestión de «a través de quién actúa el legislador» es determinada - dice Raz- en cada caso por su constitución, no existiendo una respuesta general para la misma (Raz, 1997, p. 214).

\footnotetext{
${ }^{14}$ En realidad, su postura a este respecto es algo más radical. Raz considera que exigir -como hace Marmor- que la interpretación sea siempre presentada como reveladora de una intención del autor (aunque éste sea ficticio) es algo «artificial e inútil»: «Es claro que cuando hablamos del significado de algo podemos imaginar un ser real o ficticio que intenta realizar aquello a lo que atribuimos dicho significado [pero] excepto que estén afectadas intenciones reales, hablar de intenciones hipotéticas de gente ficticia raramente es de ninguna importancia real. No nos permite progresar en nuestra comprensión de ninguna manera» (Raz, 1997, p. 207).
} 
Cuando un miembro de la legislatura vota a favor de un proyecto de ley, dice Raz, puede «intentar ganarse el favor del electorado, aparecer como valiente y decidido ante sus hijos, aliviar las aflicciones que sufren los progenitores solteros...» (Raz, 1997, p. 215). ¿Cuál de esas intenciones resulta relevante para la interpretación de la legislación? Podría pensarse que la respuesta a esta pregunta viene dada de nuevo por la constitución del cuerpo legislativo de que se trate; pero Raz considera que en este punto puede decirse algo más desde una perspectiva teórico-jurídica. La noción de «legislación» no es un concepto jurídico particular, sino general: aunque cada sistema jurídico pueda determinar quién tiene el poder legislativo y cómo debe ejercerse, lo que no puede determinar es qué es la legislación; ésta es una tarea teórica que no puede llevarse a cabo sin referirse a la «intención legislativa». La legislación es, por definición, un acto intencional, de manera que sólo los actos ejecutados con la intención de legislar pueden -en opinión de Raz- ser actos legislativos (Raz, 1997, pp. 215 y ss.). Veamos ahora cómo determina este autor el contenido y alcance de dicha intención.

La noción de legislación conlleva la idea de confiar poder sobre el Derecho en manos de una persona o institución: el legislador; y esto implica considerar que éste detenta un control voluntario sobre el desarrollo del Derecho. Sin embargo, no es extraño suponer que en ocasiones los propios legisladores desconocen los detalles de la legislación, ¿puede entonces decirse que la legislación es un acto intencional? La respuesta de Raz es que sí, y ello porque la intención exigida por su tesis es una intención «mínima». Se trata únicamente de que cuando alguien legisla ha de expresar la intención de que el texto de la ley que está votando, «comprendido como tales textos son comprendidos en la cultura jurídica de su Estado al ser promulgado en las circunstancias en las cuales éste es promulgado», sea considerado como Derecho. En otras palabras, esta intención no se refiere directamente al contenido de la legislación (al significado del texto), sino que llevaría a cabo una remisión respecto a la determinación del contenido significativo del Derecho a las convenciones dominantes ${ }^{15}$. Esta intención mínima resulta suficiente, sin embargo, para preservar la idea esencial de que los legisladores tienen control sobre el Derecho (Raz, 1997, pp. 215-219).

Por tanto, a la pregunta acerca de cuál es la intención relevante para la interpretación de las normas jurídicas legisladas, Raz responde que se trata

${ }^{15}$ Dejo aquí al margen la cuestión de que esas convenciones han de ser, según Raz, las dominantes en el momento de la promulgación de la ley, lo que implicaría dar preferencia a lo que el propio Raz denomina una «interpretación conservadora» de la ley. Sin embargo, creo que eso no implica ningún cambio respecto a las tesis aquí sostenidas. En realidad el propio Raz matiza tanto su tesis en este punto que la reduce prácticamente a la trivialidad (sobre ello, véase la siguiente nota de este artículo). Para una discusión sobre este asunto, véase Lora Deltoro, 1998, pp. 214 y ss. 
de la «intención mínima» necesaria para que cualquier acto cuente como acto legislativo. Ahora bien, Raz considera que, puesto que en algunos sistemas puede exigirse, junto a esa intención mínima, la presencia de intenciones «adicionales» (como la promoción de alguno de los fines jurídicamente estipulados exigida a la legislación subordinada en países de Common Law), dichas intenciones también podrían resultar relevantes para la interpretación de esas normas.

El argumento en el que se basa la tesis de la intención de la autoridad es, en opinión de Raz, un aspecto de la doctrina de la autoridad: la autoridad posee control sobre el Derecho sólo cuando su legislación es interpretada de este modo. Pero podría objetarse la posibilidad de que algún legislador no tuviese realmente esa intención estándar, sino que pretendiese que la ley que está votando fuera interpretada conforme a otro tipo de criterios, por ejemplo, conforme al código místico para la interpretación de los textos sagrados de una secta religiosa. Si la legislación sólo es inteligible si es interpretada mediante la intención del legislador, entonces -se pregunta Raz- ¿estarían los tribunales y los individuos en general obligados a seguir la intención del legislador de que su ley sea leída a la luz del código místico? Para que esto suceda, señala Raz, el legislador deberá expresar su intención de que así sea (pues sabe que si no lo hace, no será interpretado de esa manera, y no se puede intentar aquello que se sabe que no sucederá). Y este acto de expresión de su intención será, a su vez, interpretado como tales actos lo son normalmente, es decir, mediante las convenciones predominantes en ese tiempo ${ }^{16}$.

Hasta aquí lo que la tesis de la intención de la autoridad implica. Raz es consciente de que podría considerarse que la misma resulta vacía o irrelevante para la interpretación jurídica y, anticipándose a dicha objeción, señala, por un lado, que aunque su tesis no contiene un método para la interpretación, sino una remisión a las convenciones interpretativas predominantes en el momento de la legislación, sí que exige comprender las leyes conforme a lo que el legislador dijo, es decir, lo que sus palabras significan, dadas las circunstancias de la promulgación de la legislación y de las convenciones dominantes en ese momento, de manera que establece una severa restricción a la tarea interpretativa; y, por otro lado, recuerda que junto a la intención mínima pueden coexistir intenciones adicionales que lleguen a desempeñar un papel sustantivo en la interpretación, llegando incluso -co-

${ }^{16}$ De este modo, Raz señala que las convenciones tienen cierta prioridad sobre las intenciones, «no en el sentido de que debe seguirse la convención antes que la intención», sino en el sentido de que la intención es aquello que ha sido interpretado conforme a las convenciones interpretativas de tales expresiones (Raz, 1997, p. 220). 
mo veremos- a desplazar a la intención mínima (Raz, 1997, pp. 222-223).

Para finalizar, Raz admite la existencia de tres supuestos que pueden limitar el alcance de su tesis de la intención de la autoridad, cuando se trata de Derecho legislado y asumiendo que la autoridad es legítima. El primero hace referencia a aquellos casos en los que el objetivo del Derecho es asegurar convenciones para la coordinación. Dado que aquí lo importante es que se logre la coordinación, esta legislación -dice Raz- no necesita ser interpretada conforme a la intención (estándar) del legislador; en tanto sea interpretada de modo que asegure la convención para la coordinación, servirá completamente a la intención del legislador, aunque no se siga la convención querida por éste (Raz, 1997, p. 225).

El segundo supuesto es aquél en el que existen intenciones adicionales junto a la intención mínima, y que entran en conflicto con ésta ${ }^{17}$. La doctrina de la autoridad sugiere que a los legisladores les fue otorgada la autoridad para crear las normas que ellos pensaban con buenas razones que serían correctas. Por ello, en los casos en los que, si una ley es interpretada de acuerdo con la intención estándar, no se lograrán los resultados económicos o sociales con ella perseguidos, parece inútil -dice Raz- seguir interpretándola conforme a dicha intención. Conviene señalar que la conclusión de Raz es que la doctrina de la autoridad justifica que, en estos casos, los tribunales se desvíen de la tesis de la intención de la autoridad, no que ellos hayan de dar efecto a la intención adicional del legislador. Esto último presentaría una gran cantidad de inconvenientes, que se conectan fundamentalmente con la exigencia de que los modos de creación de Derecho se encuentren claramente determinados. La doctrina de la autoridad -dice este autor- confía poder únicamente a quien tiene autoridad, para que promulgue las normas que le parezcan justas o deseables. Si una norma, interpretada de acuerdo con la tesis de la intención de la autoridad, falla en conseguir su resultado, ello no puede considerarse como justificación para que los tribunales la interpreten de algún otro modo, porque éstos no tienen razón para creer que la autoridad habría adoptado una norma diferente; puede haber, por ejemplo, diferentes modos de lograr la intención adicional, ¿cómo saber -se pregunta Raz- cuál habría respaldado la legislatura? (Raz, 1997, pp. 225-228).

Por último, Raz menciona el supuesto de que se trate de la interpretación de una norma antigua. Cuando estamos ante una norma dictada hace mucho tiempo, puede no haber razones para seguir interpretándola de acuerdo con la intención estándar. Este argumento, señala Raz, sólo se sos-

${ }^{17}$ No se trata, por tanto, del supuesto al que se refería Marmor -y que también es asumido por Raz- en el que la intención adicional del legislador es considerada relevante para interpretar el Derecho en aquellas cuestiones en las que la intención estándar admite diversas posibilidades interpretativas. 
tendrá respecto a cuestiones en las que opiniones, gustos o circunstancias cambiantes pueden producir una diferencia entre lo que es Derecho acertado y lo que no lo es. En estos casos, los tribunales deben confrontar la cuestión acerca de si una pieza legislativa aún tiene el rango de autoridad que una vez tuvo; esto implica - dice Raz- que al interpretar leyes antiguas surgen cuestiones acerca de su fuerza obligatoria que no surgen en la interpretación de leyes recientes (Raz, 1997, pp. 228-230).

Respecto a estos supuestos que limitan su tesis, Raz señala que en los dos primeros -cuando se pretende asegurar la coordinación y cuando existen intenciones adicionales incompatibles con la intención estándar-son las mismas razones que apoyan la tesis de la intención de la autoridad las que justifican desviarse de dicha tesis o la indiferencia hacia tales desviaciones. Se trata -dice Raz- de «límites impuestos a la tesis de la intención de la autoridad al tomar nota de la intención del legislador, intención que es convertida en relevante por la doctrina de la autoridad» (Raz, 1997, p. 229). El tercer supuesto -el de las normas antiguas- es considerado más radical; implica que, en ciertas circunstancias, las razones para obedecer al Derecho legislado se vuelven independientes de la autoridad de su legislador, haciendo que la tesis de la intención de la autoridad no resulte justificada.

\section{Algunas observaciones sobre las tesis intencionalistas}

Pasaré ahora a realizar algunas observaciones sobre las tesis de Marmor y de Raz. En primer lugar, mostraré cómo estos autores no deslindan convenientemente los sentidos de «intención» que están en juego en sus exposiciones; en segundo lugar, intentaré determinar el alcance de sus tesis «intencionalistas» a propósito de la interpretación del Derecho; y, por último, lanzaré la hipótesis de que un modelo exclusivamente intencionalista o comunicativo del Derecho, como el manejado por estos autores, puede resultar inapropiado para dar cuenta de la interpretación jurídica.

\subsection{Diversos sentidos de «intención»}

Tomaré como punto de partida el análisis de Anscombe, quien distingue tres usos del término «intención» (Anscombe, 1991, p. 41). El primero es el que se encuentra en las expresiones de intención de futuro del tipo «voy a hacer tal cosa»; el segundo es el que está implícito cuando se dice que una acción es intencional; y el tercero es el que resulta relevante cuando nos preguntamos con qué intención se ha hecho algo. Pongamos un ejemplo. El 8 de junio Carmen y Pilar tomaron la decisión de enviar al día siguiente una invitación a Pedro, un amigo común, para que pasara una semana de vacaciones en su apartamento. Ambas coincidieron en los términos de redacción de la invitación y en el propósito de aprovechar los conocimientos informá- 
ticos de Pedro para instalar su ordenador, sin embargo cada una pretendía además cosas distintas con la invitación. Carmen suponía que así el año próximo Pedro las invitaría a su casa en la sierra y Pilar se había propuesto conquistar a Pedro durante su estancia en el apartamento. A partir de esta situación podríamos decir: (1) que el 8 de junio Carmen y Pilar «tenían la intención de» invitar a Pedro; (2) que la invitación -cursada al día siguientefue un «acto intencional» llevado a cabo por las dueñas del apartamento; y (3) que ambas compartían el propósito o intención de que Pedro les ayudara a instalar su ordenador; pero que también albergaban otras intenciones al actuar de ese modo: el que Pedro correspondiera con una futura invitación, en un caso; y, en el otro, crear la oportunidad para conquistarle.

Veamos algunas observaciones sobre estos usos del término «intención» que nos pueden resultar de interés. Los dos primeros usos pueden verse -dejando de lado no pocas complicaciones-como los aspectos ex ante y ex post de un mismo sentido de intención (al menos en los casos que aquí nos interesan, si una acción es calificada de intencional es porque se tenía la intención de hacerla). Este sentido de intención es el que resulta relevante para responder a la pregunta ¿qué acción ha realizado un sujeto? El tercer uso que señala Anscombe se correspondería con un sentido distinto de «intención» (los propósitos u objetivos perseguidos con la acción) y sería el sentido pertinente para responder a la pregunta ¿para qué ha realizado tal acción el sujeto? Conviene notar que para distinguir estos dos sentidos de intención necesitamos, previamente, identificar una acción respecto a la cual los vamos a predicar ${ }^{18}$. Para evitar confusiones, llamaré «intención en sentido mínimo» al primer sentido aquí señalado -el que nos permite identificar la acción- y al segundo, «propósito» o «intención ulterior». Obviamente, el contenido de la intención, en el primer sentido, siempre es relativo a una acción del propio sujeto que posee la intención. En cambio, el contenido de las intenciones en el sentido de propósitos o «intenciones ulteriores», puede ser relativo a acciones de otro sujeto o a estados de cosas que no se correspondan con el resultado de la acción de nadie, como por ejemplo la disminución del IPC. Debe señalarse, además, que una misma acción intencional puede perseguir distintos propósitos.

Volvamos a nuestra discusión. En principio, parece que las intenciones que están en juego en la primera versión del intencionalismo de Marmor o en la tesis de la intención de la autoridad de Raz se corresponden con el sentido de intención implícito en «acción intencional»: la intención en sentido

${ }^{18}$ Para un tratamiento exhaustivo de las complejidades del concepto de acción y, en particular, del papel que desempeña la «intención» en la identificación de las acciones, véase González Lagier, 2000. 
mínimo; mientras que las «intenciones ulteriores» e «intenciones en cuanto a la aplicación» de las que habla Marmor, así como las «intenciones adicionales» de Raz se corresponderían con el segundo sentido aquí señalado (los «propósitos»o «intenciones ulteriores»). Sin embargo, esta afirmación requiere algunas precisiones. Veamos primero en qué consiste exactamente la intención mínima o estándar de la que habla Raz y que supongo -Marmor no es muy explícito- coincide con la intención a la que hace referencia Marmor en su primera versión del intencionalismo. Para ello usaré el ejemplo de una acción, que al igual que la de legislar, es institucional y requiere la cooperación de más de un individuo.

Supongamos que hace unas semanas me casé. Yo realmente no quería casarme, pero una serie de circunstancias que escaparon de mis manos me decidieron a seguir adelante y dar mi consentimiento ante el juez. De hecho, intenté aunque sin éxito que el matrimonio no llegara a celebrarse. Ahora bien, si digo que «yo no quería casarme, pero me casé», ¿estoy diciendo que mi acción de contraer matrimonio fue «no-intencional»? Claramente no; contraer matrimonio, al igual que legislar, es una acción necesariamente intencional. Pero ¿qué es exactamente lo que yo hice intencionalmente? Dar mi consentimiento ante el juez (aquí no interesa cuáles fueran mis motivos: podía tener deseos enfrentados, pero quizás la intención puede considerarse algo así como un balance global de deseos, entre otras cosas ${ }^{19}$ ). Y a esa declaración mía se le atribuye (dada la existencia de ciertas reglas que confieren poderes, y siempre que se den otras circunstancias: en este caso, que el otro contrayente dé también su consentimiento) un resultado, unos efectos jurídicos ${ }^{20}$. Por lo tanto, resultaría ininteligible que yo dijera que tenía la intención (en sentido mínimo) de dar mi consentimiento ante el juez, pero que no tenía la intención (en ese mismo sentido) de contraer matrimonio o de adquirir los derechos y deberes que esa situación implica. Sería similar a si dijera que calenté intencionalmente agua hasta los 100 grados, pero que no tenía la intención de hacerla hervir.

Centrémonos en el caso de la legislación. Legislar es claramente una acción intencional. El agente que actúa en este caso es el órgano legislativo y la intención se atribuye a tal órgano, pero la atribución de dicha intención depende necesariamente de que haya algunos individuos que actúen intencionalmente de una determinada manera. ¿Cuál es la acción intencional que se les exige a los miembros del órgano legislativo, o mejor dicho, a un porcentaje de los mismos? Simplificando mucho, podríamos decir que votar a

\footnotetext{
${ }_{19}$ Sobre esta compleja cuestión, puede verse Bayón Mohíno, 1991, pp. 43 y ss.

${ }^{20}$ Sobre esto véase la concepción de las reglas que confieren poderes de Atienza y Ruiz Manero (1996, esp. cap. 2).
} 
favor de que un determinado texto se convierta en ley. Debe notarse que, dado que legislar es una actividad institucional y colectiva (sería un procedimiento que exige una serie de acciones de varios individuos), puede decirse, sin que resulte contradictorio, que un parlamentario no tenía la intención -como propósito- de que un determinado texto se convirtiera en Derecho, aunque votó -intencionalmente (con la «intención en sentido mínimo»)- a favor de ello. En realidad, un parlamentario considerado aisladamente no puede tener la «intención en sentido mínimo» de convertir un determinado texto en Derecho, porque no se trata de una acción que él pueda llevar a cabo; eso sí, puede tener la «intención ulterior» (o propósito) de que algo se convierta o no en Derecho ${ }^{21}$. Ahora bien, una vez que se llevan a cabo todas las acciones previstas en el procedimiento legislativo, se producirá un determinado resultado: el texto se convertirá en Ley (y se darán todas las consecuencias que se prevean para dicha situación: la ley pasará a formar parte del Derecho, con una determinada jerarquía, deberá ser tenida en cuenta por los tribunales...). Y para explicar este cambio normativo como una acción del órgano legislativo suele acudirse a la atribución al «legislador» de la intención de que un determinado texto se convierta en Derecho. Y este resultado, o esta atribución de intención, se producirá independientemente de lo que querían o pretendían sus miembros cuando votaron a favor del proyecto, de sus propósitos o intenciones al actuar de ese modo ${ }^{22}$. Por supuesto, esto no es obstáculo para seguir manteniendo una concepción personal de la autoridad, como la sostenida por Raz y Marmor, según la cual la legislación es un procedimiento para crear Derecho que depende de la voluntad de una serie de sujetos: aquéllos que ocupan ciertos cargos.

Pasemos al otro tipo de «intenciones», las intenciones ulteriores o adicionales y las intenciones en cuanto a la aplicación; se trata de lo que se pretende conseguir con la promulgación de determinadas normas (la consecución de ciertos fines, o que los tribunales apliquen la norma a ciertos casos). Estas intenciones se corresponderían, por tanto, con el sentido de «propósito» o «intención ulterior» antes señalado. Como hemos visto, puede decir-

${ }^{21}$ También podríamos decir que los parlamentarios pueden tener, considerados individualmente, la «intención en sentido mínimo» de contribuir a que un determinado texto se convierta en Derecho. En este caso, hemos cambiado la identificación de la acción de referencia.

${ }_{22}$ Por supuesto, puede considerarse que dicha atribución está basada en la presuposición -bastante razonable, por cierto- de que si los parlamentarios han actuado intencionalmente de un determinado modo (votando a favor de un determinado proyecto de ley) es porque los mismos pretendían que ese proyecto pasara a formar parte del Derecho.

En el fondo, tras esta observación subyacen las mismas cuestiones que están implicadas en el análisis del acto ilocucionario de mandar llevado a cabo por MacCormick y que es tomado por Bayón como punto de partida para su crítica al prescriptivismo (Bayón Mohíno, 1991, pp. 264 y ss.). 
se que a un órgano colegiado se le atribuye la «intención» (en sentido mínimo) de legislar, y que tal atribución dependerá de las reglas que configuran la constitución y funcionamiento de dicho órgano; sin embargo, la atribución de este segundo tipo de intenciones no resulta tan simple. Raz ni siquiera se plantea este problema (pues parece equipararlas a la intención mínima) y el intento de acudir a la noción de «intenciones compartidas» de Marmor no parece demasiado claro. Volvamos sobre él.

Para atribuir «intenciones compartidas» a un grupo, Marmor consideraba que era necesario exigir, junto al elemento cuantitativo, una conexión no accidental entre la intención y la identificación del grupo como tal; así, decía, hablamos de que una nación tiene la intención de adquirir la independencia, pero no de su intención de comer grandes cantidades de fresas. Pero, en mi opinión, esta atribución de intenciones lo que parece exigir no es tanto su conexión con la identificación del grupo, sino la expectativa de que la intención sea compartida por otros miembros del grupo, o por decirlo de otro modo, que exista una interacción entre la formación de las intenciones de los miembros del grupo. Así, por ejemplo, tendría perfecto sentido decir que $« 3^{\circ}$ de Derecho» tiene la intención de irse de viaje a Grecia; y no porque tenga que ver con la identificación del grupo como tal (lo que identifica a los alumnos de Derecho no es irse de viaje), sino porque esa intención no se forma independientemente de las intenciones de los otros miembros del grupo. Y así, en el caso del legislador, si bien es cierto que su función es la de dictar leyes y quizás esto sea lo que lo identifica como tal, las intenciones de, por ejemplo, disminuir la carga fiscal de un determinado sector de la sociedad o de que la norma «prohibida la entrada de vehículos en el parque» se aplique a las bicicletas no parecen tener que ver con la identificación del legislador.

Queda todavía pendiente otro problema aún mayor: la determinación de cuáles de esas intenciones ulteriores que pueden atribuirse al legislador son legítimas o jurídicamente relevantes. Volveré sobre ello más adelante.

Ahora quiero señalar algunos de los problemas que genera el no haber deslindado adecuadamente los distintos sentidos de intención. Raz parece presuponer que la intención mínima que se requiere para la identificación de algo como Derecho y los propósitos o intenciones adicionales se encuentran en un mismo nivel y que, por tanto, pueden entrar en conflicto entre sí, sin darse cuenta de que lo que hay en juego son distintos sentidos de intención y que, en sentido estricto, ni siquiera podrían predicarse ni del mismo sujeto, ni de la misma acción. Así, por ejemplo, los dos primeros supuestos que operan como límites de su «tesis de la intención de la autoridad» son presentados como dos voluntades contrapuestas del legislador: la intención mínima, por un lado, y la voluntad de que se asegure la coordina- 
ción o la consecución de determinados fines sociales o económicos, por otro. El tercer límite plantea inconvenientes aún mayores. Raz considera que, con el paso del tiempo, una norma puede perder su autoridad y eso porque, en ciertos casos, lo que era un Derecho acertado, puede dejar de serlo. Pero esa pérdida de autoridad parece difícilmente explicable desde los parámetros intencionalistas ofrecidos por el propio Raz.

\section{2. ¿Un modelo intencionalista de la interpretación jurídica?}

Veamos ahora en qué sentido puede considerarse que estas tesis defienden una postura «intencionalista» en cuanto a la interpretación jurídica.

\subsubsection{Intenciones e identificación del Derecho}

La tesis de la intención de la autoridad de Raz, al igual que la primera versión del intencionalismo de Marmor, determinarían que, para reconocer una norma como jurídica (al menos por lo que respecta al Derecho legislado), necesitamos hacer referencia a «intenciones». En el fondo, creo que esta tesis equivale a decir que la legislación es una fuente del Derecho que hace depender la creación del mismo de la voluntad de ciertos agentes, es decir, que se trata de una fuente-acto. El que ese Derecho así creado deba ser entendido, en principio, de acuerdo con las convenciones lingüísticas vigentes no requiere ninguna intención añadida. Como en el caso de cualquier texto, el significado atribuido dependerá de las convenciones vigentes en el ámbito en que se integre dicho texto; éste es precisamente uno de los presupuestos de la comunicación.

Sea como fuere, esta tesis no se relaciona directamente con la práctica de la interpretación jurídica. Por supuesto, puede considerarse -como hace Raz- que el texto identificado como Derecho, junto con el significado atribuible al mismo según las convenciones vigentes, constituirá el objeto de la interpretación y en ese sentido limitará dicha actividad, pero eso no implica que ésta sea una tesis «intencionalista» respecto a la interpretación del Derecho o, al menos, respecto al método interpretativo ${ }^{23}$. En todo caso, y como ha señalado el propio Raz (1996), la tesis determinaría por qué hay que interpretar en el Derecho (o lo que es lo mismo, por qué en el Derecho consideramos que ciertas normas están dotadas de autoridad), pero no cómo hay que hacerlo.

\subsubsection{Intenciones e interpretación del Derecho}

La segunda versión del intencionalismo de Marmor se refería al papel de las intenciones ulteriores o aplicativas en la interpretación del Derecho

\footnotetext{
${ }^{23}$ En este mismo sentido se pronuncia Lora Deltoro, 1998, pp. 136-146.
} 
legislado. La aplicabilidad de la tesis se limitaba a aquellos casos en los que la legislatura es correctamente calificada como experta sobre el tema particular que ha promulgado, y hasta el punto en que lo sea en relación con sus sujetos. Su tesis no posee, por tanto, una fuerza absoluta; y además, para que esas intenciones resulten relevantes para la interpretación, Marmor señala que previamente deben haber sido identificadas y atribuidas a los legisladores, así como consideradas legítimas o jurídicamente relevantes (lo que, según él, implica acudir a consideraciones de naturaleza moral). Las intenciones en cuanto a la aplicación se encuentran además subordinadas a las intenciones ulteriores, por lo que, a las limitaciones señaladas, se añade la exigencia de llevar a cabo un juicio de idoneidad medio a fin.

¿Hasta qué punto puede éste considerarse como un modelo intencionalista de la interpretación jurídica? Lo que Marmor defiende es que si un legislador es realmente experto en la materia en que ha legislado, entonces a la hora de interpretar sus leyes está justificado acudir a sus intenciones (si éstas existen, resultan identificables y legítimas). Pero en el momento en que surja la menor duda sobre su pericia, sobre la idoneidad de sus juicios, sobre el mantenimiento de las circunstancias que dieron origen a la norma, etc., dichas intenciones deberán ser desatendidas. De este modo, lo que la tesis de Marmor parece implicar es que, para apoyar una determinada interpretación en el Derecho, puede acudirse a las intenciones de los legisladores, siempre y cuando existan argumentos independientes a favor de la corrección del contenido de dichas intenciones. Y esto es muy distinto que considerar que el criterio de corrección de la interpretación jurídica viene dado por la adecuación del significado atribuido a las normas, a las intenciones de sus creadores, que sería lo que un modelo intencionalista de la interpretación parecería exigir.

\subsection{Interpretación y modelos de Derecho}

Hemos dejado abiertos algunos problemas que planteaban las tesis intencionalistas de Marmor y de Raz en relación con la interpretación jurídica. Recordémoslos. Por un lado, Marmor no conseguía precisar el criterio para determinar qué intenciones han de considerarse legítimas o jurídicamente relevantes y, por tanto, qué intenciones deben ser tenidas en cuenta en la interpretación jurídica. Este autor establecía un criterio parcial y negativo: deben rechazarse las intenciones que el legislador no esté dispuesto a confesar, criterio que -en su opinión- debía ser complementado acudiendo a consideraciones de naturaleza principalmente moral.

Por otro lado, hemos visto que Raz planteaba como conflictos entre distintas «intenciones» del legislador (sin mayores precisiones) los casos en que estaría justificado apartarse del sentido literal de las normas, y admitía 
además un límite a la aplicabilidad de su tesis (en el caso de las normas antiguas) que ponía en duda la base de su concepción, considerando que hay casos en los que la autoridad de las normas se desvincula de la autoridad de sus autores. Si mi análisis no está equivocado, la tesis de la intención de la autoridad de Raz supone que la legislación es una fuente de creación deliberada de Derecho; lo que implica que los textos aprobados de acuerdo con el procedimiento establecido deben ser considerados como pertenecientes al Derecho y que su significado depende de las convenciones lingüísticas vigentes. Pues bien, en mi opinión no es necesario admitir ni excepciones ni límites a esta tesis. Una cosa es el significado que, en principio, deba atribuirse a un texto legislativo (lo que Marmor llama el «significado semántico») y otra muy distinta el que los tribunales, en algunos casos, pueden apartarse de ese significado cuando en su tarea aplicativa deben interpretar el Derecho.

En un trabajo anterior defendí la tesis de que la peculiar perspectiva desde la que se analiza el Derecho influye en la caracterización de la actividad interpretativa (Lifante, 1999, pp. 22-23). Distinguí entonces dos grandes enfoques del Derecho: el enfoque de las normas generales y el enfoque del caso. Desde el primero, el Derecho es visto como un conjunto de normas generales que provienen básicamente de una serie de autoridades y cuya función primordial es guiar y coordinar la conducta futura de los ciudadanos. Para el segundo enfoque, el Derecho es fundamentalmente un mecanismo de resolución de conflictos; el principal problema es aquí cómo reconstruir los distintos materiales jurídicos (provenientes de una diversidad de autoridades) para buscar una solución jurídica al caso ${ }^{24}$. Mi tesis hoy iría, sin embargo, algo más lejos. Creo que para dar cuenta satisfactoriamente de la interpretación jurídica es necesario adoptar un modelo de Derecho que asuma, en alguna medida, la segunda perspectiva de análisis. En el ámbito jurídico, las decisiones adoptadas por cualquier instancia jurídica -incluyendo las interpretaciones- deben presentarse como justificadas jurídicamente, lo que supone que sean acordes con «el Derecho». De este modo, lo que caracterizaría a la interpretación jurídica como tal sería precisamente llevar a cabo el tipo de actividades reconstructivas propias del segundo enfoque.

Como es sabido, Raz sostiene la tesis de que todo el Derecho «está basado en fuentes», lo que para él implica que ha de poder identificarse haciendo referencia exclusivamente a hechos sociales. Con esta exigencia, Raz se opone expresamente a la «tesis de la incorporación», según la cual también sería Derecho lo que se considera implícito en el Derecho basado

\footnotetext{
${ }^{24}$ Se trata de las actividades que se suelen agrupar bajo el impreciso nombre de «método jurídico». Cfr. Aguiló Regla, 2000, pp. 148-154.
} 
en fuentes, y a la «tesis de la coherencia» de Dworkin (Raz, 1985, pp. 295 y ss.). Se trata claramente de un modelo de Derecho que opta por el primero de los enfoques aquí señalados. Y es precisamente desde este modelo de Derecho, construido a partir de su relación con la noción de autoridad, desde el que Marmor aborda todo el tema de la actividad interpretativa. Pues bien, la imposibilidad de dar una solución adecuada a los problemas antes señalados apunta -en mi opinión- precisamente al hecho de que la interpretación jurídica es una actividad que no puede llevarse a cabo, y por tanto tampoco explicarse, si no se adopta una perspectiva global del Derecho, si éste no es concebido como un todo que pretende dar una solución a los problemas que se le planteen. Y esta perspectiva de análisis está muy lejos de la adoptada por Raz y Marmor. Estos autores parten de su «modelo comunicativo de Derecho», según el cual el Derecho es básicamente un producto de actos de comunicación, y pretenden abordar las peculiaridades de la interpretación jurídica utilizando la relación tripartita típica de cualquier situación comunicativa (Emisor $\rightarrow$ Mensaje $\rightarrow$ Receptor), y que, en el caso del Derecho, vendría constituida por los siguientes elementos:

Legislador $\rightarrow$ Texto legislativo $\rightarrow$ Intérprete

Pero este esquema es demasiado pobre. El intérprete jurídico no se encuentra sólo con un texto (creado por una determinada autoridad legislativa) que ha de ser interpretado, sino que ese texto se integra en una práctica social (en la que conviven -entre otras cosas- muchos otros textos y autoridades); y el significado que ha de atribuírsele mediante la interpretación debe ser el significado «según el Derecho».

Podemos ahora replantear la oposición entre el modelo interpretativo de Marmor (intencionalista o comunicativo) y el de Dworkin (constructivo o dependiente de valores) que se supone ha dado origen a esta discusión. Como señalé al principio, no tiene sentido preguntarse cuál de los dos modelos es el acertado para dar cuenta de la «interpretación en general», sino que las diferencias deben situarse, en su caso, en las particularidades señaladas por cada uno de estos autores para la específica «interpretación jurídica».

Dejemos al margen las complejidades de la concepción dworkiniana y quedémonos con lo que serían los rasgos centrales de su modelo interpretativo. La interpretación es una actividad basada en valores, cuyo objetivo es presentar el objeto interpretado bajo su mejor ángulo; es decir, desarrollar al máximo los valores propios de su género. La actividad interpretativa implica - para Dworkin- llevar a cabo un proceso reconstructivo de los materiales jurídicos en el cual se establezcan los valores y objetivos perseguidos por ese Derecho y se determine qué interpretación los desarrolla en mayor medida. 
Pues bien, las «intenciones ulteriores» que Marmor considera relevantes para la interpretación jurídica (y a las que subordina el otro tipo de intenciones: las aplicativas) no parecen ser algo distinto a los valores o fines que se pretenden desarrollar a través de ese Derecho (¿qué otra cosa, si no, puede querer decir su exigencia de que se trate de «intenciones jurídicamente relevantes»?). Interpretar requerirá así llevar a cabo un proceso reconstructivo del Derecho que nos determine cuáles son esos valores y qué concreta interpretación es la que los desarrolla en mayor medida (recordemos aquí el sometimiento de las intenciones aplicativas a las ulteriores). Por otro lado, los límites que Raz admitía a su tesis de la intención de la autoridad resultan bastante similares a lo que, desde una perspectiva como la dworkiniana, se presenta como exclusiones de ciertos materiales jurídicos que, en ocasiones, deben llevarse a cabo para poder reconstruir de manera unitaria el Derecho.

En definitiva, creo que el modelo de interpretación jurídica construido por Marmor (o mejor dicho, las aportaciones que a este tema pueden encontrarse en sus tesis) no resulta incompatible con el modelo sostenido por Dworkin. Se trata, eso sí, de un modelo construido desde una distinta concepción del Derecho y que arrastra bastantes deficiencias para dar cuenta de tal actividad.

\section{Bibliografía}

AGUILÓ REGLA, Josep (2000). Teoría general de las fuentes del Derecho (y del orden jurídico), Ariel, Barcelona.

ANSCOMBE, G.E.M. (1991). Intención, trad. de Ana Isabel Stellino, ediciones Paidós, Barcelona-Buenos Aires-México.

ATIENZA, Manuel; y RUIZ MANERO, Juan (1996). Las piezas del Derecho. Una teoría de los enunciados jurídicos, Ariel, Barcelona.

BAYÓN MOHÍNO, Juan Carlos (1991). La normatividad del Derecho. Deber jurídico y razones para la acción, Centro de Estudios Constitucionales, Madrid.

DWORKIN, Ronald (1986). Law's Empire, Belknap Press, Harvard.

ENDICOTT, Timothy A.O. (1994). «Putting Interpretation in its Place», en Law and Philosophy, 13, 1994, pp. 451-479.

GONZÁLEZ LAGIER, Daniel (2000). Las paradojas de la acción. Una introducción para juristas a la teoría de la acción humana, en prensa.

GRICE, H.P. (1991). «Las intenciones y el significado del hablante», trad. de J. José Acero, en Luis Ml. Valdés Villanueva (ed.), La búsqueda del significado, Tecnos, Madrid, pp. 481-510. 
LIFANTE VIDAL, Isabel (1999). La interpretación jurídica en la teoría del Derecho contemporánea, Centro de Estudios Políticos y Constitucionales, Madrid.

LORA DELTORO, Pablo de (1998). La interpretación originalista de la Constitución. Una aproximación desde la Filosofía del Derecho, Centro de Estudios Políticos y Constitucionales, Madrid.

MARMOR, Andrei (1992). Interpretation and Legal Theory, Clarendon Press, Oxford.

MARMOR, Andrei (1995). «Autoridades y personas», trad. José Juan Moreso y Pablo E. Navarro, en Doxa, $\mathrm{n}^{\circ}$ 17-18, pp. 303-330.

RAZ, Joseph (1985). «Authority, Law and Morality», en The Monist, vol. 68, pp. 295-324.

RAZ, Joseph (1996). «¿Por qué interpretar?», trad. Rolando Tamayo y Salmorán, en Isonomía, $\mathrm{n}^{\circ}$ 5, pp. 25-40.

RAZ, Joseph (1997). «La intención en la interpretación», trad. de José Juan Moreso y Pablo E. Navarro, en Doxa, n 20, pp. 199-233.

RÓDENAS CALATAYUD, Ángeles (1996). Sobre la justificación de la autoridad, Centro de Estudios Constitucionales, Madrid.

WALDRON, Jeremy (1995). «Legislators' Intentions and Unintentional Legislation», en Andrei Marmor (ed.), Law and Interpretation (Essays in Legal Philosophy), Clarendon Press, Oxford, pp. 329-356. 
$\triangle \quad$ DOXA 22 (1999) 